\title{
A prestação pelo setor público não estatal dos serviços de saúde pública: análise de hipóteses e potencialidades
}

\author{
Laís Silveira Costa; Paulo Marques e Taís R. Borges
}

\section{Introdução}

A Constituição Federal preconiza a saúde como direito de todos e dever do Estado e, adicionalmente, estabelece um formato de federação cooperativo e não hierarquizado entre as três esferas de governo, que são autônomas. O modelo pressupõe que a União, estados e municípios responsabilizem-se por atuar complementarmente para a prestação dos bens e serviços públicos (FerRAz, 2007). Em conjunto, as três esferas de poder garantem a defesa de direitos sociais e condições de cidadania da população.

A saúde foi o setor social pioneiro neste movimento de descentralização. A municipalização decorrente redefiniu a arena decisória, colocando os gestores municipais como responsáveis diretos pela administração e execução da rede de serviços do Sistema Único de Saúde (SUS). São implementados, a partir disto, novos modelos assistenciais, no nível local e sob a responsabilidade do poder público municipal, organizados para responder às necessidades de saúde da população. 
As condições de oferta desses serviços, entretanto, sofrem impacto das diversas capacidades operacionais e gerenciais de cada um desses entes federados, traçando um forte quadro de desigualdade na oferta dos mesmos. A relevância do estabelecimento de novos modelos de gestão, capazes de garantir os direitos preconizados na Constituição, pauta-se na transferência de responsabilidade da prestação de serviços de cunho social para os municípios, aliada às restrições fiscais e à limitação da capacidade de gestão desses.

É nesse contexto que se volta o olhar para novas modalidades de interseção entre o público e o setor público não estatal, no âmbito do desenvolvimento de estratégias gerenciais do Estado. O fortalecimento da cooperação entre o Estado e o terceiro setor para a prestação de serviços públicos de saúde pressupõe a estruturação de elementos regulatórios, de um arcabouço institucional e de estratégias de governança, além de determinação política.

O objetivo deste trabalho é analisar as potencialidades dessas alianças no setor $\mathrm{da}$ saúde, partindo-se das estratégias estabelecidas na Reforma do Aparelho do Estado que, entre outras coisas, estimulou a publicização de setores considerados não exclusivos do Estado, mas de interesse estratégico desse - caso da saúde ${ }^{1}$. Buscouse justamente o fortalecimento da aliança entre o Estado e o terceiro setor, estratégia aprovada pela Lei 9.637/98 - a Lei das Organizações Sociais.

A seguir, detalha-se a atuação das organizações sociais (OS), principal modelo de prestação de saúde em parceria com o não estatal, indicando algumas hipóteses possíveis e os desafios e questões adicionais para acompanhamento e regulação das OS, além de passos e questões críticas para a criação da lei e para a estruturação de parcerias em saúde entre o poder público e o terceiro setor. Posteriormente, são traçados os desafios enfrentados por esse modelo de gestão. $\mathrm{O}$ trabalho apresenta ainda a análise de alguns estudos de casos em que são apresentados pontos críticos para o estabelecimento dessas parcerias e seus resultados. Finaliza-se com breves considerações sobre o tema.

\section{A saúde e a reforma do apa- relho do Estado: novos formatos da relação entre o público e o privado}

O cenário de crise fiscal dos anos 1990 , aliado às diretrizes impostas pela globalização, que preconizam a diminuição do Estado e o movimento pela democratização dos serviços sociais, reforçaram a tendência de municipalização da gestão da atenção à saúde. Institucionalmente, a Constituição Federal de 1988 avançou na descentralização, a partir da definição da repartição de recursos, mas não estabeleceu claramente como essa cooperação entre os entes federados deveria ocorrer. Nos anos posteriores a 1988, houve uma acomodação pactuada das responsabilidades que cada ente teria em relação aos serviços públicos - que, no caso da saúde, pioneira no processo, institucionalizou-se pelas suas leis orgânicas e pelas Normas Operacionais Básicas do SUS (NOBs) e pela Norma Operacional da Assistência à Saúde do SUS (NOAS).

Vale enfatizar que, de uma forma ou de outra, a pactuação e descentralização desses serviços não eram suficientes para atender às demandas impostas pela velocidade do desenvolvimento tecnológico; e vem se observando, desde então, a necessidade de implantação de novos modelos de atenção à saúde, conforme atesta Nascimento (2007). 
O aumento da complexidade e da pressão da demanda contextualizado em um modelo de gestão do Estado burocrático e mobilizado pela atenção apenas aos processos e não também aos resultados a serem entregues para a população, reforçava a inadequação das regras da administração pública para a atenção à saúde e, em particular, no que se refere à gestão hospitalar. De acordo com Santos (2007, p.2), esse formato dificultava "uma política de incorporação tecnológica, informatização, modernização administrativa e gestão de recursos humanos comprometidos com o serviço público", caso particularmente limitante para a administração de hospitais e de serviços ambulatoriais.

Dessa forma, os princípios norteadores do SUS, com sua respectiva descentralização, voltados para maior eficiência e abrangência dos serviços de saúde, encontravam no "engessamento dos trâmites burocráticos" um sério entrave à prestação pública de saúde (CostA, 2005, p.18).

É nesse contexto, considerado por Mansur (2007) como inadequado e rígido, com limitada autonomia de gestão - tanto de pessoal quanto de insumos e financeiro -, apresentando dificuldade de interação com sistemas loco-regionais, ingerência político-partidária e fragilidade à alternância democrática, que se insere a proposta de reforma do aparelho do Estado. A reforma administrativa do Estado brasileiro, promovida pelo então Ministério da Administração Federal e Reforma do Estado (MARE), em 1995, visou modernizar sua gestão, propondo, para tanto, um modelo gerencial de gestão por objetivos e estabeleceu estratégias para a modernização da administração pública ${ }^{2}$.

A reforma, segundo o Mare, fundamentou-se em uma administração pública mais eficiente, voltada para o fortalecimento da cidadania, cujos pressupostos foram os de maior qualidade, otimização dos recursos, ênfase nos resultados, orientação cliente-cidadão via controle social, maior governança e governabilidade. No bojo dela, ocorreu uma redefinição do papel do Estado, repassando a terceiros a responsabilidade direta da prestação de bens e serviços, fortalecendo, em contrapartida,

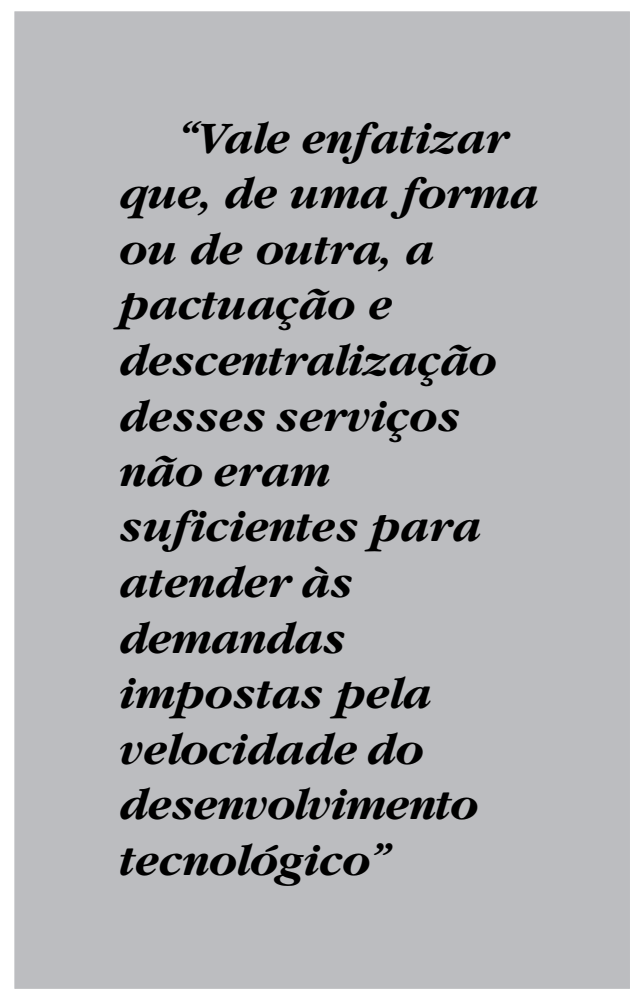

seu papel como promotor, regulador e fiscalizador da prestação dos serviços.

Uma de suas estratégias foi a aprovação do Programa Nacional de Publicização ${ }^{3}$ (Lei 9.637/98 - Lei das OS) de alguns setores, reconhecidos como os não exclusivos do Estado, mas estratégicos, que poderiam adotar o modelo de gestão gerencial. Visou a flexibilização de 
estratégias administrativo-financeiras, entre elas: as relações trabalhistas e a aquisição de bens e serviços e a própria dispensa de licitação nos contratos de prestação de serviços entre as OS e a administração pública (art. 17 da Lei 9.637/98), motivada pela necessidade de qualificação dos recursos humanos ante a complexificação das demandas e a necessária agilidade da ação pública.

Essa publicização materializa-se pela atuação de organizações do terceiro setor, de direito privado e sem fins lucrativos, na prestação de bens e serviços públicos não exclusivos do Estado, como é o caso da saúde, educação e cultura. Nas palavras de Costa (2005, p.11),

"Tratava-se (...) de um movimento portador de um novo modelo de administração pública, baseado no estabelecimento de alianças estratégicas entre Estado e sociedade, tanto para atenuar supostas disfunções operacionais daquele quanto para otimizar os resultados das ações sociais em geral."

Argumentos contrários a essa estratégia referem-se à precarização das relações trabalhistas decorrentes da sua flexibilização, à falta de controle sobre os gastos públicos e ao arrefecimento do controle social.

Quanto às relações trabalhistas, o argumento perde força ao se verificar que a prestação de serviço de saúde pelo ente público já era realizada substancialmente por meio de terceirizações de recursos humanos e compra de serviços especializados, anteriormente ao fomento à publicização. Esta, além disso, pelo menos garante a aplicação das leis trabalhistas definidas pela Consolidação das Leis do Trabalho $(\mathrm{CLT})^{4}$, de forma mais estruturada, uma vez que deve ser definida em contrato de gestão, conforme determina a lei, ou por meio de convênios estabelecidos entre as partes e instrumentos análogos.

Quanto aos gastos públicos, há mecanismos para coibir as más práticas, e serão mencionados neste trabalho. De toda forma, pode-se adiantar que as localidades mais avançadas na adoção das parcerias entre o público e o terceiro setor já possuem análises comparativas entre os modelos, realizadas em alguns casos por organismos externos à gestão, que mostram, em sua maioria, a eficiência do gasto público quando gerido pelo setor público não estatal.

Em relação ao controle social, o documento do Mare de 1995 afirma que a publicização tende a ser um fator que agrega eficiência, uma vez que os conselhos de administração das organizações sociais envolvem vários segmentos de beneficiários (sociedade civil), apontando a vantagem evidente de que o controle "deixa de basear-se nos processos para concentrar-se nos resultados" (MARE, 1995, p.16). Além disso, em contraposição à prática observada na gestão pública, as OS têm suas metas avaliadas periodicamente e divulgadas regularmente, reforçando os instrumentos de controle social.

Institucionalmente, de acordo com a orientação federal, as OS assumem uma entidade estatal previamente existente, ou novas atividades cujo arranjo estrutural é financiado pelo Estado. A garantia dos preceitos da ação pública e da gerência por resultados se materializaria na formulação do contrato de gestão, que define as obrigações das partes. Essa é outra questão apontada pelos defensores da publicização, em resposta às críticas a possível malversação de recursos públicos, no caso de conduta inadequada pela empresa do terceiro setor na gestão do bem público. 
Uma vez que as OS assumem a integralidade do patrimônio público, elas respondem juridicamente pelos atos cometidos, além do controle processual que permanece a cargo dos tribunais de contas. Além disso, assumem responsabilidade quanto aos fins a serem atingidos, diferentemente do que se observa hoje com as formulações mais tradicionais de terceirização dos serviços públicos, caso em que a entidade pública é quem responde pelos desvios diversos do parceiro contratado ou conveniado (COSTA, 2005).

Um ano depois da regulamentação das OS, publicou-se a Lei 9790/99, regulamentada pelo Decreto 3.100/99, conhecida como a Lei das Oscip (Organização da Sociedade Civil de Interesse Público). Apesar da crescente adesão ao modelo das Oscip, conforme afirma Barbosa (2007, p.73-74), a maioria das entidades dos setores de saúde e de educação não se identifica com essa qualificação ${ }^{5}$, o que a autora atribui à impossibilidade de as instituições acumularem outros títulos e qualificações, a não ser por período não superior a dois anos, depois reformulado para período de cinco anos, momento em que a entidade deverá optar pelo título de sua preferência.

Dada a não difusão das Oscip, a análise aqui desenvolvida focar-se-á nas experiências das OS. Vale enfatizar que as breves questões aqui apontadas acerca das OS não são definitivas na análise de sua potencialidade de melhoria da gestão subnacional da saúde, dado que tratam de questões genéricas, no sentido de que se referem essencialmente a prática pautada pela Lei federal. De toda forma, o modelo federal tem servido como ponto de partida para a elaboração das legislações estaduais e municipais, que adicionalmente incorporam ajustes ao modelo federal, para adequarem-se às características da gestão subnacional. Para a análise deste trabalho, importa avaliar os estudos de caso, os desafios apresentados e os modelos que possam fornecer uma base de informações capaz de subsidiar a atuação local dos municípios.

\section{As organizações sociais na prestação da saúde}

\section{Desafios para a implementação do modelo de OS}

Nos últimos anos, vários impedimentos e desafios marcaram a trajetória do desenvolvimento do modelo de publicização via OS $^{6}$. Costa e Ribeiro (2004) apontam os três principais: baixa difusão e conhecimento sobre as OS, alto custo político para realizar a conversão dos hospitais estatais em modelos OS e a forte vinculação desse modelo à agenda política da coalizão do Partido da Social Democracia Brasileira com o Partido da Frente Liberal (PSDB-PFL).

Ibañez et al. (2001), por sua vez, chamam atenção para a importância da regulação baseada em um olhar sobre a demanda e não sobre a oferta, como ocorre historicamente, assim como para a importância da regulação que contemple indicadores de processos, além de resultados, relativos às atividades administrativas, de recursos humanos e de sistemas de informação. Os autores acrescentam que a regulação não deveria restringir-se aos aspectos formais, o que impossibilitaria as inovações desejadas, mas deveria incorporar um olhar sistêmico do setor.

Mansur (2007) aponta alguns desafios; entre eles, a necessária melhoria da eficiência da alocação de recursos, que implica o conhecimento das necessidades e prioridades de saúde, um bom controle 
de qualidade e metas e um sistema de informações eficiente. Acrescenta que o contrato deve pautar-se pela necessidade de incentivar procedimentos eficientes, e que o parceiro não estatal precisa ser hábil para promover as mudanças administrativas e organizacionais necessárias e adequar as funções administrativas - como, por exemplo, o desenvolvimento e qualificação da função de compra e a capacitação e profissionalização dos agentes.

Ressaltam-se ainda os desafios referentes à adaptação organizativa e funcional; a necessária viabilidade financeira relacionada à melhoria da eficiência na produção dos serviços; a autonomia real da gestão, o que às vezes não ocorre na prática; o desenvolvimento de políticas de incentivo e participação; e a melhoria da capacidade de gestão e apoio à tomada de decisão pautados no conhecimento de características, custo e qualidade de serviço.

Taylor (2003) detalha os desafios específicos da limitação da capacidade gerencial do Estado, como, por exemplo, a dificuldade de definição das metas e expectativas de desempenho a serem contratualizadas; de negociação dos termos e condições contratuais; de monitoramento dos contratos e de sua própria implementação; além da seleção dos potenciais parceiros adequados.

Já a análise das dificuldades, realizada por Costa (2005), enfatiza o fato de que o processo de mudança organizacional tem ocorrido de forma fragmentada, exigindo, na busca da qualidade gerencial, a qualificação das pessoas envolvidas e a estrutura de absorção das mudanças. Além desses, menciona o forte constrangimento do contrato de gestão. Este deveria garantir autonomia na definição de plano de cargos e salários, elaboração de normas próprias para a contratação e seleção, regulamento próprio de compras e contratação de serviços, liberdade de execução financeira dentro do contrato de gestão e orçamento global de recursos pactuado. O que minimizaria os efeitos da flexibilização da administração, questão essa relacionada com regras inadequadas, resistências diversas à iniciativa e dificuldade de planejamento da distribuição dos riscos.

Montone (2008) aponta como principais desafios à iniciativa a necessidade de fortalecimento desse modelo de contratação de serviços de saúde; a institucionalização das OS na estrutura políticoadministrativa das secretarias municipais de saúde; e o aprimoramento dos conteúdos técnicos e das ferramentas de controle e avaliação.

Por fim, informações prestadas pela Secretaria Municipal de Saúde do Rio de Janeiro (SMS-RJ) ressaltam como os principais riscos no estabelecimento da parceria com o terceiro setor: a burocratização; a carteira de serviços inadequada; os mecanismos de pagamento não incentivadores; sistemas de monitoramento insuficientes; a inadequação da relação entre contratador e provedor; e o excesso de interferências políticas na função de contratação.

Essas são questões que, em maior ou menor grau, têm dificultado a efetividade do modelo e contribuído para a resistência observada em relação a ele. Os próximos tópicos deste trabalho, referentes às organizações sociais, abordam propostas de diversos autores para a superação dessas questões, assim como detalham os passos para a publicização via OS.

\section{Etapas para a criação da lei mu- nicipal \\ A definição de um ambiente propício ao estabelecimento de parcerias entre setor público e público não estatal baseia-se nos}


princípios de legalidade, impessoalidade, moralidade, publicidade e eficiência, conforme determina o art. 37 da Constituição Federal (CF) de 1988. O pressuposto brasileiro de que o administrador público só pode fazer aquilo que a lei determina exige que as iniciativas estejam claramente definidas no âmbito da legislação.

O artigo 199 da CF legisla acerca da possibilidade do setor privado atuar complementarmente ao público. A Lei 9.637/ 98 trata das hipóteses de estabelecimento de parcerias com o setor privado sem fins lucrativos para a prestação de uma gama de serviços públicos, incluídos os de saúde.

As leis orgânicas da saúde determinam diretrizes e princípios para a prestação dos serviços em território nacional, assim como preveem que a iniciativa privada poderá participar do SUS, em caráter complementar (Lei 8.080/90, art. $4^{\circ}, \$ 2^{\circ}$ ), matéria regulada adicionalmente pela Portaria 3.277/06, do Ministério da Saúde, em que se estabelece a prioridade do setor privado sem fins lucrativos para a prestação do serviço de saúde suplementar (art. $4^{\circ}$ ). Dito isso, a disciplina legal é harmoniosa em relação à possibilidade de prestação de serviços de saúde pública por entes privados sem fins lucrativos.

Quando a gestão da saúde for exercida por ente público, a gestão de pessoal regese pelo Regime Jurídico Único, planos de carreira, concursos públicos e contratações autorizadas pelo setor público, regras essas flexibilizadas pela Lei das OS.

$\mathrm{Na}$ definição de leis em âmbito municipal, as regras para contratação e gestão de pessoal devem estar claramente definidas, mas também devem garantir a flexibilização necessária para a boa gestão pública. De forma análoga, buscou-se excetuar a obediência à Lei 8.666/93 (alterada pela Lei 8.883/94), que rege as licitações e contratos da administração pública, no caso da gestão exercida pelo terceiro setor, importando, entretanto, a definição de regras transparentes para aquisições e planos de investimentos, a fim de garantir a economicidade das transações com recursos públicos.

Para se conseguir os benefícios da administração gerencial, a regulamentação a ser criada deve planejar uma gama de características, garantindo que a autonomia

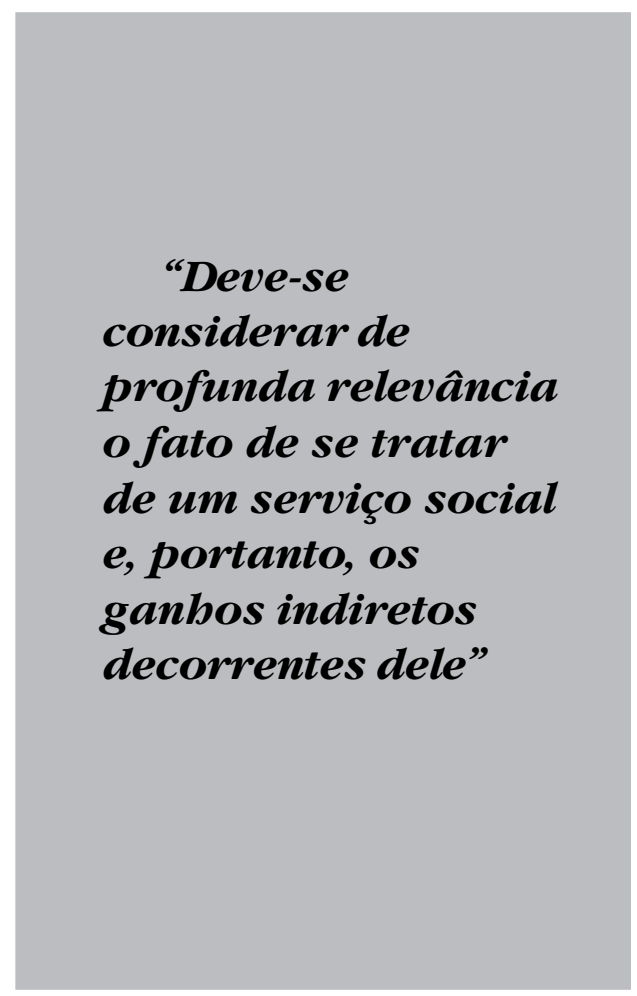

concedida gere efetividade na ação pública não estatal. De acordo com Ibañez e Netto (2007, p.1836), é fundamental estabelecer a subordinação dos produtos, serviços e iniciativas contratados às políticas de saúde do nível de governo em questão, de modo a evitar o aprofundamento da fragmentação - já existente-do sistema, o que teria resultados dramáticos para a gestão da saúde. 
Essa subordinação deve ser um pressuposto da norma a ser criada, e os objetivos e metas a serem pactuados no contrato de gestão devem contemplá-la. Entretanto, os referidos autores ressaltam que se deve tomar cuidado para não criar constrangimentos legais excessivos, que levariam a um controle cartorial que coibiria os ganhos de efetividade almejados com tal parceria. A ideia é de fato desenhar um instrumento eficiente na repartição das responsabilidades e proporcionar autonomia para a gestão da OS contratada.

Note-se que o próprio formato do contrato de gestão, observado nas experiências existentes, permite revisões periódicas dos serviços prestados, de forma que a gestão pública qualificada passe a ter condições de manter a gestão da saúde coordenada em seu território e região de atuação.

A segunda questão apontada pelos autores enfatiza a necessidade de manter princípios de legalidade na parceria estabelecida, de modo que:

"a lei que cria a alternativa deve ser clara nas diferenças que propõe (gestão orçamentária, gestão de pessoal, gestão de material e contratos, gestão da estrutura organizacional e cargos).”

Vale mencionar que há sistemas utilizados na administração pública para aquisição de bens que podem ser utilizados nessas iniciativas sem gerar efeitos colaterais indesejáveis para gestão, ou seja, sem burocratizá-la, como o sistema de pregão eletrônico e registro de preços.

Ibañez e Neto (2007) apontam o princípio da eficiência como o terceiro pressuposto a ser incorporado no desenho da parceria. Pautam seu argumento na ineficiência da gestão pública observada atualmente e em questões outras já debatidas neste trabalho. Enfatizam que a estrutura organizacional deve ser fixada pela organização e alterada sempre que conveniente, em clara alusão à necessária autonomia e responsabilização pactuadas no contrato de gestão.

Por fim, os autores mencionam uma das fragilidades atualmente observadas, considerada crucial para a boa gestão da saúde em parceria com o setor público não estatal: a capacidade de controle. Os órgãos historicamente responsáveis por esse controle no Brasil (Tribunal de Contas, Ministério Público, entre outros) têm a tradição de realizar apenas o controle dos meios, o controle processual, em vez de olhar também para os resultados da ação pública.

O controle da administração gerencial demanda outro olhar e, por conseguinte, pressupõe outra forma de ser exercido. Essas parcerias com o setor público não estatal pressupõem também controles de processo, atribuídos a um conjunto de objetivos alcançados, materializados em produtos e/ou serviços entregues, além do controle do resultado final. Esse controle configurar-se-ia como importante fonte de avaliação que subsidiaria qualitativamente as análises e repactuações periódicas dos contratos de gestão.

Hoje, a administração pública, mesmo no nível federal, no qual já se observa algum avanço, não está qualificada para trabalhar esse controle. Ela não entende a sua dinâmica, tem dificuldade de desenhá-lo e, mais ainda, de incorporá-lo ao seu cotidiano. Estudo realizado por Costa e Ribeiro (2004) aponta a dificuldade de o Estado exercer controle e de criar sistemas simples e informatizados de acompanhamento como um grande empecilho à qualificação 
e ao sucesso da iniciativa. Nesse sentido, os autores apontam, como ponto crítico das parcerias, a qualidade dos registros efetuados pelos hospitais.

A importância do desenvolvimento de sistemas de informação simplificados, apontada pelos autores, é corroborada pelo modelo de publicização apresentado pelo município do Rio de Janeiro, em que se enfatiza o papel central desses sistemas para a eficiência da prestação e reavaliações constantes e necessárias aos periódicos ajustes do contrato de gestão.

Ibañez e Neto (2007) compartilham das conclusões apresentadas ao afirmarem que o Estado brasileiro precisa melhorar a capacidade de exercício de controle dos recursos disponíveis para as OS no exercício da gestão do público, não exclusivo do Estado, tanto no que se refere à execução quanto ao alcance de resultados.

Para tanto, é necessário um sistema de informação simplificado, objetivo e automatizado na apresentação das análises para subsidiar o acompanhamento e controle. Os autores apontam ser esse o grande desafio do Estado, enfatizando que a maior liberdade de atuação sob a Lei 8.666 não pode trazer em seu bojo sinonímia com favorecimento de fornecedores e clientelismos na escolha e contratação de recursos humanos.

\section{Passos para a publicização, alguns modelos e sugestões}

$\mathrm{Na}$ implantação da parceria com o setor público não estatal do Estado de São Paulo, o primeiro passo foi estabelecer o que se pretendia exatamente do novo modelo e em que grau ele deveria compor e participar da política. Partindo-se daí, buscou-se definir a especificidade da lei a regulamentar as OS no território, a situação da gestão de saúde do estado e a rede de serviços existentes (Ibañez et al., 2001).

A adaptação do modelo para atuação dos municípios deve contemplar a verificação acerca de o governo municipal possuir ou não a matéria regulamentada em lei. A experiência sugere que a institucionalização da iniciativa por meio de lei própria ${ }^{7}$ garante mais governabilidade. Ademais, deve-se verificar não somente as características da saúde na localidade em questão, mas também como o município se insere na regionalização do SUS. Essa questão é detalhada por Nascimento (2007), ao enfatizar a importância do gestor municipal no processo de definição e concepção de estratégias que promovam a noção de rede, para evitar a ruptura e fragmentação do sistema.

Além da definição dos mecanismos de controle dos serviços entregues, Nascimento (2007) aponta para a necessidade de se verificar a eficácia da relação estabelecida no tocante aos custos adicionais dessa nova modalidade de gestão, que devem ser compensatórios.

Deve-se considerar de profunda relevância o fato de se tratar de um serviço social e, portanto, os ganhos indiretos decorrentes dele, tendo em vista não somente a otimização dos recursos financeiros e humanos, mas também a eficiência e qualidade da assistência, assim como a ampliação dos serviços, o aumento da produtividade, a implantação de normas, rotinas e protocolos, a agilidade operacional e a modernização administrativa (Oliveira, 2007). A transferência dessa modernização deve ser planejada, de modo a ampliar os ganhos com o modelo.

Já a SMS-RJ aponta como elementoschave: o estabelecimento de um marco de referência; apoio político; desenvolvimento técnico e força dos instrumentos básicos 
(contrato, sistema de pagamentos e de informação); compromisso e força institucional; liderança estratégica; adequação organizativa flexível adaptada a cada fase de desenvolvimento da contratação.

Ainda de acordo com a SMS-RJ, os instrumentos básicos da relação com o terceiro setor são o contrato de serviços de saúde, a carteira dos serviços, o sistema de pagamento, os mecanismos de monitoramento, acompanhamento e avaliação e o sistema de informações. Os requisitos básicos demandam o desenho do processo de contratação de serviços; dos modelos básicos de contratos de serviços; do processo de faturamento; dos sistemas de pagamento e contraprestações; e dos sistemas de monitoramento e acompanhamento, além da adequação dos sistemas de informação, da normatização legal e administrativa e da própria organização em relação aos requerimentos de contratação (SMS-RJ).

De acordo com Ibañez e Neto (2007), o contrato deverá tratar da definição da missão da OS e definir precisamente os produtos e usuários, os objetivos e metas, assim como a estrutura organizacional e a tecnologia a serem utilizadas na gestão da OS. Deverá prever metodologias na área de planejamento, avaliação de desempenho, informatização de recursos humanos e estrutura de custos, bem como regulamentar especificamente as condições em que ocorrerão investimentos. As questões específicas concernentes à autonomia, regulação e desempenho relacionam-se à prestação de contas e implicam a responsabilização referente ao interesse público (Fleury apud Ibañez e Neto, 2007).

A garantia de que os contratos de gestão funcionem de fato como um instrumento de gestão estratégica pressupõe a determinação das responsabilidades e compartilhamento dos risco, de acordo com Mansur (2007). Sugere o autor que o gestor do SUS deve assumir o controle da oferta; direcionar a ação governamental; partir de uma base de avaliação que contraponha o desempenho atual e o desejado; contratualizar os níveis tanto de responsabilidade quanto de responsabilização; garantir mecanismos de controle social; e atrelar o financiamento à produtividade. Isso tem sido uma marca dos bons contratos, cuja deficiência ocorre mais frequentemente quando há dificuldades operacionais e cognitivas para acompanhamento dos resultados. Quanto à contratada, Mansur (2007) aponta as seguintes responsabilidades: desenho do plano operacional para a prestação de serviços; pactuação das regras para administração e restituição de bens e recursos; definição do limite para gastos com pessoal e regras claras de contratação; normatização da remuneração e vantagens.

Os contratos de gestão estabelecem também a duração das parcerias, que majoritariamente são renováveis a cada 12 meses e repactuadas trimestralmente, o que pode implicar ajustes dos valores financeiros nessa periodicidade. O pagamento destinado ao custeio de recursos humanos e manutenção é realizado mensalmente. O pagamento de atividades específicas, como apoio à integração, pode ser pactuado por contraprestação de relatórios e estabelecimento de cronogramas.

Usualmente o pagamento tem sido realizado em partes fixas, que contemplam $90 \%$ dos recursos, e variáveis, para os $10 \%$ restantes. As regras para o pagamento da parcela variável e os indicadores a serem observados devem ser pactuados e estabelecidos no contrato de gestão, não havendo espaço para subjetividade nessa relação. 
De forma análoga a dos indicadores, as comissões de avaliação devem ser estabelecidas contratualmente. Observa-se frequentemente ampla participação de diversos representantes, tais como a Secretaria de Fazenda e Administração do município, além da de Saúde, cujos representantes extrapolam a atividade finalística (departamento de controle e regulação), Conselho Municipal de Saúde, Câmara Municipal, etc. Há experiências bemsucedidas em alguns hospitais geridos por parcerias público-privadas, que levam para a composição dessas comissões de avaliação representantes de usuários, trazendo para dentro do sistema a retroalimentação da qualidade dos serviços prestados.

Note-se, entretanto, que a participação dos atores no acompanhamento da gestão, por si só, não garante sua qualidade. Os representantes chamados para compor o acompanhamento são capacitados e habituados a avaliar as ações apenas processualmente. Sem capacitá-los para a análise também de resultados, a tendência, observada em diversas experiências, é manter o formato existente, que não é compatível com a proposta de modelo de administração gerencial. O acompanhamento a partir dos resultados alcançados, ou não, permite uma avaliação objetiva do que precisa ser alterado na repactuação dos contratos.

Pelo próprio histórico da relação do setor da saúde com o setor privado, normalmente há barreiras diversas à legislação e à adoção dessa relação. É importante ressaltar que a realização de encontros, consultas e seminários voltados para explicar o modelo e para detalhar não somente seus objetivos, como também esclarecer dúvidas clássicas de seus opositores - como, por exemplo, o fato de que as relações trabalhistas podem ser favorecidas, em vez de prejudicadas, e de como o contrato de gestão pode permitir não somente o uso eficiente, mas também o uso efetivo dos recursos públicos - pode ajudar a dirimir parte das dúvidas, assim como diluir resistências do Legislativo e da população local. Ademais, seria interessante a apresentação de resultados de casos exitosos, como os que se multiplicam em São Paulo, que podem ser ilustrativos do que motiva e embasa a adoção da

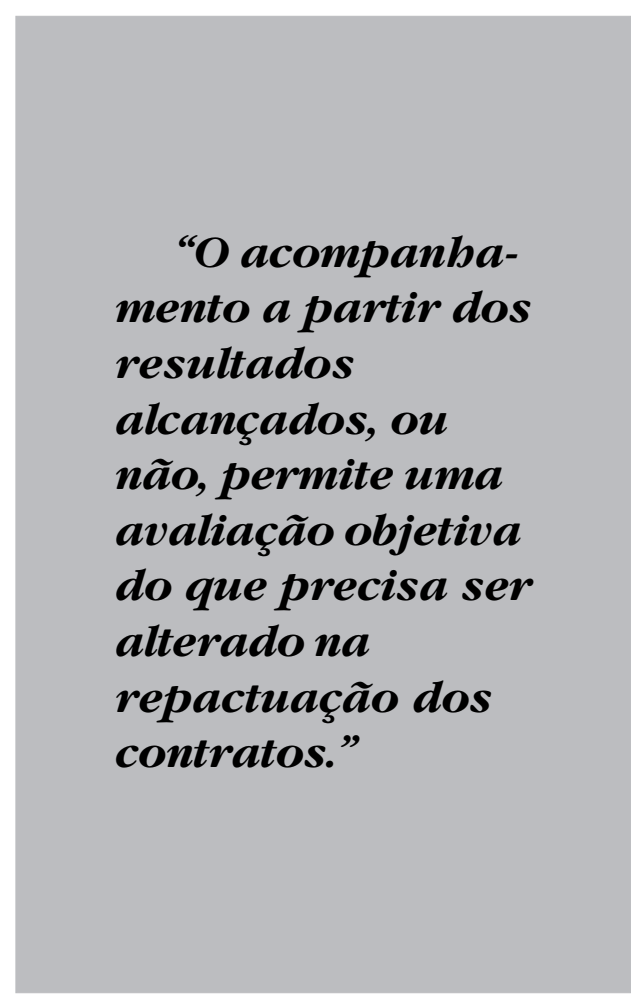

publicização: a prestação da atenção à saúde, conforme preconizada pela Constituição como direito de todos.

Sant'Anna et al. (2007:131) enfatizam que o apoio da população pode ser a garantia da manutenção do modelo, quando há mudanças de representantes na gestão pública, e ressaltam ainda que a participação de usuários de serviços e representantes da comunidade nos Conselhos 
de Avaliação configura-se como desejável inovação introduzida por alguns municípios.

\section{Estudo de casos}

As parcerias estabelecidas entre OS e o Estado vêm se multiplicando em território nacional. Entretanto, mais frequentemente encontra-se, na literatura, estudos de casos em São Paulo, onde essa atuação ocorre há uma década. No referido território, a parceria entre o setor público e o público não estatal foi adotada como uma estratégia de gestão do setor da saúde. A importância da análise dos casos em São Paulo também advém do fato de que lá essas políticas foram adotadas com caráter sistêmico e regional e, portanto, tratou-se de situar a iniciativa de forma integrada ao modelo de gestão do estado, com a devida priorização dela e do desenvolvimento de instrumentos capazes de transformá-la em uma ferramenta administrativa gerencial de maior sucesso.

É importante ressaltar que, para Piola e Vianna (2009), o modelo de gestão via OS, adotado no Estado de São Paulo, difere daquele proposto nos Cadernos Mare de Reforma do Estado de publicização de serviços não exclusivos do Estado. Em São Paulo, a iniciativa foi incentivada pela existência de hospitais construídos com empréstimos do Banco Mundial (e, mais tarde, equipados com recursos públicos), mas que o estado não poderia gerir diretamente, uma vez que essa operação implicaria gastos em recursos humanos que excederiam os limites definidos na Lei de Responsabilidade Fiscal.

Portanto, a diferenciação entre os dois modelos consistiria no fato de que "a lei federal está direcionada à criação de OS que resultem de unidades estatais que seriam posteriormente extintas, dentro do processo de 'publicização', enquanto em São Paulo não houve 'publicização', mas sim contratação de uma organização privada sem fins lucrativos anteriormente existente e de idoneidade reconhecida para gerir hospitais novos" (Piola e Vianna, 2009, p.61).

Ibañez et al. (2001) apontam três dimensões de contexto para pautar a avaliação e análise da nova política, de acordo com estudo exclusivo da experiência paulista: a legitimidade e potencialidade da regulamentação legal das OS, como modelo organizativo e organizacional do SUS; antecedentes e situação atual do gestor público e da rede de serviços do estado; e a avaliação do desempenho a ser alcançado pelas OS.

A primeira dimensão aponta para a definição do alcance das organizações sociais e de seu papel no processo de modernização do serviço público, situando o papel das OS nas medidas de gestão estratégica do Estado. Os argumentos contrários à adoção desse modelo, à época, destacaram duas questões principais: a hipótese alternativa de gestão via administração indireta, nas suas diversas formas, e um desvio no modelo do SUS ao passar da administração pública para a esfera privada. Ambos argumentos estão fragilizados pela motivação original de se criar as organizações sociais no setor da saúde, uma vez que a rigidez do modelo de administração pública vigente (burocrático e processual) não vem permitindo a gestão adequada do setor, de modo a atingir seu objetivo primordial preconizado pela Constituição, que é a prestação da atenção à saúde como direito de todos.

A análise dos antecedentes e da situação atual, segunda dimensão apontada, permite levantar os entraves ao sistema, rever sua articulação, a infraestrutura instalada, seus 
resultados atuais e os que precisam ser atingidos. Apontam-se, entre outras coisas, as falhas e ineficiências do setor a serem superadas. Servem como instrumentos de verificação das mudanças necessárias, não somente gerenciais, mas também de infraestrutura, para a alteração de um modelo de gestão voltado para o alcance de objetivos e resultados (terceira dimensão).

Em relação ao estudo de casos, Sant'Anna et al. (2007) fornecem análise complementar no que se refere aos modelos de OS existentes em São Paulo, apontando que um deles reproduz o modelo federal, regulado por lei subnacional. Mas afirmam que existe também um segundo modelo, em que o estado cria uma lei para qualificar as entidades para prestação de serviços a serem publicizados, sem, para tanto, participar do órgão diretivo da entidade. Os autores afirmam que esse tipo de publicização propõe basicamente um contrato com terceiros, que pode ter outras atividades, mantendo as demais características do contrato de gestão.

Em análise aos dois modelos, Sant'Anna et al. (2007) acreditam que o segundo funciona mais como uma terceirização, prevendo, entretanto, alguns instrumentos mais aptos para o exercício de controle social, como a comissão de avaliação. E que nesse sentido, dado que o setor público tão somente participa desses conselhos, torna-se ainda mais importante a qualificação de seus representantes na função de controle de resultados e procedimentos, extrapolando os também necessários controles processuais.

Note-se que o modelo de São Paulo trouxe inovações importantes: originalmente, atuou em "organizações hospitalares que só existiam como planta física" (em obras de hospitais iniciadas e inacabadas), em vez de realizar a conversão de unidades da administração direta já existentes (CosTA e Ribeiro, 2004, p.30). De acordo com os autores, isso acabou representando baixo custo político para o governo e oportunizou a operação de um grande contingente de hospitais em curto prazo de tempo. Em citação a Motta, os autores afirmaram que o envolvimento de múltiplos participantes (empresas, universidades, institutos de pesquisa, sistema financeiro, legal, instituições de ensino, mecanismos diversos de seleção de parcerias e governo) foi também fator de sucesso da iniciativa, que passa a caracterizar-se a partir de um "sistema setorial de inovação".

Entre os principais fatores de sucesso na experiência de São Paulo, Costa e Ribeiro (2004) apontam a sustentabilidade da iniciativa, implantada em 1998 e com crescente número de unidades; sua blindagem jurídica; e a transparência de sua implementação. Afirmam ainda que a experiência em São Paulo é bastante rica na análise da evolução desse instrumento de publicização, em especial porque, ao longo do tempo, foram incorporados ajustes e estruturas diversas para aperfeiçoar essa gestão.

Entre elas, vale mencionar a criação de mecanismos de incentivo e responsabilização no que se refere ao financiamento, que, a partir de 2001, é realizado por meio de um formato híbrido, em que $90 \%$ do orçamento é fixo e transferido em parcelas mensais, e 10\% é variável, ligado a indicadores de qualidade, o que tem conferido autonomia ao modelo de gestão em análise. Ademais, o estado desenvolveu metodologia de efeito redutor de remuneração da parte fixa, baseado em critérios de qualidade, pactuados no contrato de gestão, que pode levar a perdas de até 30\% do orçamento contratado (COSTA, 2004). Adicione a esses a monta de $10 \%$ do valor 
fixado, referente ao valor variável que também pauta-se pelo desempenho da atuação da OS, e pode-se afirmar que o modelo de São Paulo tem seu financiamento e sustentabilidade substancialmente marcados pelo desempenho organizacional das organizações, conforme ressaltam Costa e Ribeiro (2004).

Por fim, os autores apontam outra evolução do Contrato de Gestão, no que se refere ao controle e avaliação: a implantação de sistema de custos hospitalares padronizado, a instituição da Comissão de Acompanhamento para cada hospital, a definição das atribuições e funções específicas dos interlocutores e a padronização da apresentação dos dados (Costa e Ribeiro, 2004). Esse modelo, concluem os autores, tem trazido resultados práticos, observados em estudo comparativo entre doze OS paulistas e dez hospitais públicos. Tal estudo permitiu verificar a tradução do ganho de eficiência na qualidade da gestão da saúde.

No caso do município de São Paulo, Montone (2008) aponta como principais resultados dessas parcerias: o desenvolvimento de ferramentas de gestão dos contratos, o aprimoramento de conteúdos técnicos e incremento da organização técnico-administrativa da Secretaria Municipal de Saúde. O autor afirma ainda que, para garantir a qualidade da gestão, criouse um Núcleo Técnico de Contratação de Serviços de Saúde, voltado essencialmente para planejamento, acompanhamento e controle técnico dos contratos, gestão administrativa e financeira e sistemas de informação. Observou-se, no município, ampla distribuição de contratos de gestão a fim de complementar a prestação de serviços de saúde, sendo eles, em parte, direcionados a microrregiões/territórios de saúde, para serviços diagnósticos, gestão hospitalar e também prontosocorros.

Costa (2005) dedicou sua monografia do curso de Especialização em Administração Hospitalar em Gestão da Qualidade de Saúde, na Universidade Estadual do Ceará, ao estudo da análise da eficiência das organizações sociais e realizou estudo de caso de um hospital público e de um publicizado. Apresentou resultados promissores em relação à nova ferramenta de gestão da utilidade pública. A autora enfatiza que, dado o universo restrito da análise, não é possível fazer inferências acerca do modelo como um todo. De toda forma, seu estudo foi criterioso e apontou que a instituição gerida pela OS mostrou desempenho substancialmente melhor na prestação dos serviços de saúde.

\section{Considerações finais}

Com a democratização do país e o consequente advento de uma nova correlação de forças sociais e políticas, as temáticas da descentralização e do poder local ganham força, constituindo-se em marcos importantes para o debate e para as propostas sobre a organização do Estado brasileiro e redefinição de suas funções. Parte-se da constatação de que um Estado centralizado é ineficiente nas políticas setoriais e dificulta o controle social (BARATTA et al., 1992).

Motivadas pela necessidade e embasadas em alguns aspectos positivos da reforma do Estado, proliferaram, no Brasil, experiências na área da administração pública objetivando maior flexibilidade gerencial para compra de insumos e materiais, contratação e dispensa de recursos humanos, gestão financeira de recursos, além de priorização de resultados, satisfação dos usuários e qualidade dos 
serviços prestados (IBAÑEZ et al., 2001). No âmbito da reforma, o Programa Nacional de Publicização representou a estratégia voltada para estimular a participação do terceiro setor na prestação de serviços públicos considerados estratégicos, porém, não exclusivos do Estado. Motivou-se pelo esgotamento de um modelo burocrático da administração pública, marcado por baixa capacidade gerencial, aliado à descentralização preconizada na Constituição Federal de 1988, às pressões do sistema previdenciário e às restrições fiscais, o que levou o setor público a buscar alternativas para o desempenho de suas funções finalísticas.

A reforma proposta em 1995 foi aprovada por meio da Lei 9.637/98; entretanto, questões políticas diversas, além da própria falta de continuidade do processo de reforma, levaram a que, uma década depois, o relacionamento entre o público e o público não estatal, para a prestação de serviços de utilidade pública, ainda seja fortemente marcado por um mosaico institucional.

No setor da saúde, as experiências mais relevantes de adoção do modelo de parceria entre o setor público e o público não estatal via OS encontram-se em São Paulo, cuja lei estadual para regulamentar o tema data também de 1998. Características específicas da atuação naquele território e a forte preocupação com o embasamento legal da iniciativa, aliada à sua intensa adoção, permitem verificar exemplos exitosos naquele estado.

O trabalho aqui desenvolvido intencionou analisar os principais desafios da gestão da saúde pelas OS e sugerir passos e procedimentos que deveriam compor o planejamento e desenvolvimento da publicização do setor, visando subsidiar a atuação de municípios de pequeno porte. Vale enfatizar que a experiência sugere que reside no detalhamento do contrato de gestão, em seu embasamento jurídico institucional (dado que a lei não é nacional) e na capacidade gerencial do representante público, no tocante ao acompanhamento (sem mencionar o apoio político à iniciativa), a possibilidade da publicização configurar-se como efetiva ferramenta da gestão do público. E que há maior chance de êxito nos casos em que a parceria é tratada pelo Executivo como uma das estratégias de desenvolvimento no longo prazo. Nesse sentido, um movimento de implantação de OS deve ser precedido de análise da missão dessa empreitada e de sua relação com as prioridades do Estado.

É fato que os desafios ainda são diversos, em especial no que se refere à falta de conhecimento da iniciativa, à pouca clareza de quais regras devem pautar sua gestão e como garantir que, de fato, elas possam trazer inovações para o bojo da gestão pública, além de como implantar princípios de economicidade e garantir resultados. Exemplos práticos, entretanto, sugerem que a publicização do setor da saúde via OS merece ser estudada com atenção, dado que os ganhos na capacidade de gestão dessas instituições têm se revertido para uma atenção da saúde mais qualificada e humana.

Acredita-se que o trabalho aqui apresentado levanta questões diversas que podem auxiliar no desenho de iniciativas de parceria público e público não estatal, baseado em documentos analíticos atuais sobre o tema.

(Artigo recebido em novembro de 2009. Versão final em setembro de 2010.) 


\section{Notas}

Trabalho desenvolvido no âmbito do Projeto BR-M1054, programa para subsidiar a estruturação e desenvolvimento de modelos de microalianças público-privadas (APP), desenvolvido pelo BID em parceria com o Instituto Brasileiro de Administração Municipal (IBAM).

1 Pelo Plano Diretor da Reforma do Aparelho do Estado, são considerados setores estratégicos do Estado: educação, saúde, cultura e pesquisa científica.

2 É válido relembrar que "Nos anos 90, embora o ajuste estrutural permaneça entre os principais objetivos, a ênfase deslocou-se para a reforma do Estado, particularmente para a reforma administrativa". (Bresser apud Silva Jr., João dos Reis e Sguissardi. Novas faces da educação superior no Brasil - Reforma do Estado e mudança na produção. CDAPH). Neste sentido, entre os quatro desdobramentos da chamada crise do Estado levantados por Bresser - crise fiscal, crise do modo de intervenção, crise do aparelho do Estado e crise da política -, serão tratadas neste texto apenas as questões diretamente ligadas ao terceiro aspecto dessa.

3 Publicização é definida pelo documento do Mare como o processo de transferência da produção de serviços competitivos ou não exclusivos do Estado para o setor público não estatal.

4 Santos (2007, p.4), em referência às questões trabalhistas, pontua que "o descalabro das contratações de consultores por organismos internacionais para atuar na administração pública, (...) em funções desde as mais singelas às de maior complexidade" levou a um quadro em que se observam profissionais trabalhando há mais de dez anos com contratos de consultoria - contratos esses que não garantem quaisquer direitos trabalhistas ou outros meios de proteção social do trabalhador.

5 Este comentário refere-se à esfera federal, pois estados, na definição de suas prioridades de publicização, exercem forte influência sobre os modelos a serem adotados.

6 É importante ressaltar que alguns autores questionam se o modelo adotado em São Paulo, por exemplo, deveria ser cunhado de "publicização", questão que será tratada mais adiante.

7 A Lei 9.637 é federal e não nacional. Cabe aos municípios decidirem se legislam a iniciativa ou pautam-se na Constituição e na lei orgânica para contratualizar suas parcerias.

8 Compartilhamento de riscos e sua relação com as receitas não parecem claros no modelo das OS, conforme concluem Costa e Ribeiro (2004).

\section{Referências bibliográficas}

Baratta et al. A microgestão privada da educação e da saúde no município de Maringá. Rio de Janeiro: IBAM/ENSUR, 1992.

Barbosa, M.N.L. A experiência dos Termos de Parceria entre o Poder Público e as Oscips. Ciclo de seminários novos modelos organizacionais. Seminário III: OS, OSCIP, Fundação Estatal de Saúde. Governo do Estado de São Paulo: Cepam , 2007. p. 65-95.

Brasil. Mare. Plano Diretor da Reforma do Aparelho do Estado. Ministério da Administração Federal e Reforma do Estado. Brasilia, novembro de 1995. 
CostA, N.Q. Organização Social - alternativa eficiente à gestão pública? Estudo de caso em um hospital público e um publicizado da Rede de Saúde do Estado do Ceará. (Monografia do curso de Especialização em Administração Hospitalar em Gestão da Qualidade e Sistemas de Saúde do Centro de Estudos Sociais Aplicados, da Universidade Estadual do Ceará). Fortaleza, CE, 2005.

Ferraz, L. Parceria público-público: contrato de programa e execução de serviços públicos municipais por entidade da administração indireta estadual. Revista Eletrônica de Direito Administrativo Econômico (REDAE), Salvador (Instituto Brasileiro de Direito Público), no 10, maio/junho/julho 2007. Disponível em: http://www.direitodoestado.com.br/ redae.asp. Acesso em: $1^{\circ}$ de agosto de 2009.

Ibañez, N. \& Neto, G.V. Modelos de Gestão do SUS (Management models and Brazil's National Health System (SUS). Ciência \& Saúde Coletiva, vol.12 (Supl), p.1831-1840, 2007. Ibañez, N.; Bittar, O.J.N.V.; Sá, E.N.C.; Yamamoto, E.K.; Almeida, M.F. \& Castro, C.G.J. Organizações Sociais de saúde: o modelo do Estado de São Paulo (Social health organizations: the São Paulo State model). Ciência \& Saúde Coletiva, v. 6 (2), p.391-404, 2001.

IPEA. Piola, S.F; Vianna, S.M (org). Estado de uma nação: textos de apoio. Saúde no Brasil: algumas questões sobre o Sistema Único de Saúde (SUS). Brasília, 2009.

Mansur, N. S. Avaliação dos Modelos de Organização no SUS. In: Ciclo de seminários novos modelos organizacionais. Seminário III: OS, OSCIP, Fundação Estatal de Saúde.Governo do Estado de São Paulo: Cepam, 2007.

Montone, J. O sistema de parcerias com o terceiro setor na cidade de São Paulo. II Congresso Consad de Gestão Pública - Painel 23: inovações gerenciais na saúde. Paraná, 2008.

Nascimento, V.B. Novas Ferramentas de Gestão Pública em Saúde. Ciclo de seminários novos modelos organizacionais. Seminário III: OS, OSCIP, Fundação Estatal de Saúde. Governo do Estado de São Paulo: Cepam, 2007. p. 11-19.

Oliveira, MF. Hospital Municipal Dr. José de carvalho Florence de São José dos Campos. Ciclo de seminários novos modelos organizacionais. Seminário III: OS, OSCIP, Fundação Estatal de Saúde. Governo do Estado de São Paulo: Cepam, 2007. p.21-29.

Sant'Anna Jr, A; Araújo, F.F.; Cruz, M.C.M.T. \& Silva, V.M. Estudo sobre novas formas de organização nos municípios. Ciclo de seminários novos modelos organizacionais. Seminário III: OS, OSCIP, Fundação Estatal de Saúde. Governo do Estado de São Paulo: Cepam, 2007. p.119-136.

SANTOS, L. Da Reforma do Estado à Reforma da Gestão Hospitalar Federal: algumas considerações. Seminário III: OS, OSCIP, Fundação Estatal de Saúde. Governo do Estado de São Paulo: Cepam, 2007.

TAYlor, R.J. Contracting for Health Services. In: Harding, A. and Preker, A.S.(editors) Private participation in Health Services. Washington D.C: BIRD/BM, 2003. p.157-218. 


\section{Resumo-Resumen-Abstract}

A prestação pelo setor público não estatal dos serviços de saúde pública: análise de hipóteses e potencialidades

Laís Silveira Costa, Paulo Marques e Taís R. Borges

O trabalho analisa a potencialidade do desenvolvimento de alianças entre o público e o privado na gestão pública municipal brasileira da saúde. A relevância da questão pauta-se na transferência de responsabilidade da prestação de serviços de saúde para os municípios, posterior à promulgação da Constituição Federal, aliada à limitação da capacidade de gestão dos mesmos. As análises aqui tratadas referem-se às alianças previstas no arcabouço legal brasileiro, estabelecidas entre o ente público e o terceiro setor. Essas alianças são introduzidas pela reforma do aparelho do Estado, em 1995, no âmbito da qual se utilizou a estratégia de publicização que tratou do fortalecimento dessa aliança entre o Estado e o Terceiro Setor. A partir dos modelos possíveis de parcerias com o terceiro setor, este estudo apresenta uma análise do modelo das organizações sociais (OS), trazendo à luz estratégias e desafios para sua implementação.

Palavras-chave: Saúde pública, terceiro setor, gestão pública

La prestación de los servicios de salud pública por el sector público no estatal: análisis de hipótesis y potencialidades

Laís Silveira Costa, Paulo Marques y Taís R. Borges

El trabajo analiza la potencialidad de desarrollo de alianza entre público y privado en la gestión pública municipal de salud brasileña. La relevancia de la cuestión está en la transferencia de responsabilidad de la prestación de servicios de salud para los municipios, que se da posteriormente a la promulgación de la Constitución Federal, y aliada a la limitación de la capacidad de gestión de estes. Los análisis que se hacen aqui están relacionados con las alianzas previstas en la estructura legal brasileña, hechas con los entes públicos y el tercer sector. Estas alianzas son introducidas por la reforma del aparato del Estado, en 1995. En el ámbito de esta se utilizó la estrategia de "publicização", que cuidó del fortalecimiento de la alianza entre Estado y Tercer Sector. Desde los posibles modelos de alianza con el tercer sector, este estudio presenta un análisis del modelo de las organizaciones sociales (OS), sacando a la luz estrategias y retos para su implementación.

Palabras clave: Salud pública, tercer sector, gestión pública

The public health services offer from non-state public service: hypothesis analysis and potentialities

Laís Silveira Costa, Paulo Marques and Tais R. Borges

The article analyses the potential of improving alliances between the public and private sector at the municipal level of health management. Its relevance lies on the importance the transfer of responsibility for health care services to the municipal level has had since the promulgation of the Brazilian Federal Constitution, given municipal governments' management capacity limitations. The analysis presented is in reference to alliances between the public and the third sector, as established by the Brazilian Law. Such alliances began at the time of the State machine reform, in 1995, which led to a publicizing strategy used to strengthen associations between the State and the third sector. From a number of possible models for partnerships with the third sector, this study presents an analysis of the social organizations model (SO), bringing to light strategies and challenges to its implementation.

Keywords: public health, third sector, public management 
Laís Silveira Costa

Doutoranda em Saúde Pública pela Escola Nacional de Saúde Pública Sérgio Arouca (ENSP)/Fundação Oswaldo Cruz (Fiocruz) e Coordenadora Acadêmica do Grupo de Pesquisa em Inovação e Saúde da Fiocruz/RJ. Contato: achelais@hotmail.com

Paulo Marques

Doutor em Educação pela Universidade Estadual de Campinas (UNICAMP) e Coordenador-Geral de Projetos de Capacitação da Diretoria de Desenvolvimento Gerencial da Escola Nacional de Administração Pública (ENAP). Contato: paulo.marques@enap.gov.br

Taís R. Borges

Mestranda em Economia Política Internacional pela Universidade Federal do Rio de Janeiro (UFRJ) e pesquisadora do Grupo de Pesquisa em Inovação e Saúde da Fiocruz/RJ. Contato: taisrborges@gmail.com 
